\title{
La prevalencia entre protección de derechos fundamentales o elementos de la naturaleza del cargo*
}

\section{The prevalence between protection of fundamental rights or elements of the nature of the charge}

\section{Fernando Antonio Moreno González* \\ Lina Stefania Arévalo Sanabria**}

Fecha de recepción: 12 de octubre de 2018

Fecha de aprobación: 18 de enero de 2019

\section{RESUMEN}

Este artículo pretende esclarecer los lineamientos jurisprudenciales en torno a la estabilidad laboral reforzada de los servidores públicos provisionales y la de los de libre nombramiento y remoción. Se determinan así los criterios para su amparo y el alcance de este en cada caso, sin perjuicio de los elementos naturales de su nombramiento. De esta forma, se establece que los provisionales son cobijados extensivamente, pese la transitoriedad de su vinculación.

* Artículo producto del proyecto de investigación "Estabilidad laboral reforzada en nombramientos provisionales y de libre nombramiento y remoción”, gestionado en la Universidad Libre, Bogotá. Citar como Moreno González, F. y Arévalo Sanabria, L. (2019). La prevalencia entre protección de derechos fundamentales o elementos de la naturaleza del cargo. Via Inveniendi et Iudicandi, 14(2), 89-117. DOI: https://doi. org/10.15332/19090528.5040

** Abogado. Especialista en Docencia Universitaria, Derecho Administrativo y Derecho Tributario. Magíster en Derecho Penal y Criminología. Magíster en Derecho Administrativo. Actualmente docente de las universidades Libre, Colegio Mayor de Cundinamarca y La Gran Colombia. Doctorando de la Universidad de Buenos Aires. Asesor jurídico de la Secretaría General del Instituto Nacional de Medicina Legal y Ciencias Forenses. Correo electrónico: fernandomorenogonzalez@yahoo.es. Orcid: https://orcid.org/0000-0003-2785-0171

*** Abogada. Especialista en Derecho Administrativo. Estudiante de Maestría en Derecho Administrativo. Abogada de la Secretaría General del Instituto Nacional de Medicina Legal y Ciencias Forenses, Bogotá, Colombia. Correo electrónico: arevalosanabria.l@hotmail.com. Orcid: https://orcid.org/0000-0002-6748-1553 
VIeI Revista Virtual

Via Inveniendi et Iudicandi

Lo contrario ocurre con los servidores de libre nombramiento y remoción pues el amparo de sus derechos fundamentales es excepcionalísimo, aunque se encuentren en alto riesgo de vulneración.

Palabras clave: estabilidad laboral, derechos fundamentales, servicio público.

\begin{abstract}
This article aims to clarify the jurisprudential guidelines regarding the reinforced labor stability of the provisional public servants and those of free appointment and removal, thus determining the criteria for their protection and the scope thereof, without prejudice to the natural elements of his appointment. In this way, it was possible to determine that, in the case of the provisional ones, they are extensively sheltered despite the transience of their relationship, otherwise, it happens with the free appointment and removal servers, which, the protection of their fundamental rights is exceptional, although the risk of their violation is immersed.
\end{abstract}

Keywords: Labor stability, fundamental rights, public service. 
Fernando Antonio Moreno González, Lina Stefania Arévalo Sanabria La prevalencia entre protección de derechos fundamentales o elementos de la naturaleza del cargo

\section{INTRODUCCIÓN}

Atendiendo a la dinámica de la función pública en Colombia, se han determinado a lo largo de la legislación, la doctrina y la jurisprudencia mecanismos para proteger a aquellos vinculados laboralmente con el Estado. Se trata de garantías que sobrepasen las características particulares de cada vinculación y permitan una unificación en cuanto se trate del amparo a derechos fundamentales de los servidores públicos.

La Constitución Política de 1991 estableció en su art. 125 que la vinculación a la administración por regla general será mediante carrera administrativa. Vinculación caracterizada por el mérito de quien ingresa al empleo público. Estas altas capacidades del funcionario le otorgan garantías especiales dentro de su servicio a la Administración. Entre ellas, una estabilidad de orden reforzado, la cual indica una serie de protecciones que no permiten una desvinculación arbitraria por parte del nominador. A contrario sensu, para que esta última se dé es necesario el cumplimiento de un procedimiento determinado que vincule la evaluación de desempeño y el incumplimiento de las obligaciones legales y reglamentarias.

Pero la vinculación a la Administración puede darse igualmente mediante otro tipo de nombramientos, caracterizados por la permanencia transitoria de quienes ocupan el respectivo cargo. Dicha temporalidad del empleo hace que su estabilidad no sea naturalmente reforzada, sino variable según la vinculación que tenga el funcionario y su situación particular. En lo intrínseco del empleo público existe, como una de las excepciones constitucionales a la carrera administrativa, la vinculación de servidores mediante libre nombramiento y remoción, excepción consagrada en el art. 125 superior. Esta ocurre cuando por razones de confianza deben ocupar cargos directivos de manejo y orientación institucional personas con determinadas calidades académicas y profesionales.

Los funcionarios de libre nombramiento y remoción, por lo especial de sus funciones, requieren para su vinculación y retiro de la discrecionalidad del nominador. Esta característica especial se conoce como estabilidad laboral precaria ya que únicamente se requiere que el nominador persiga el interés general con la desvinculación para que esta sea efectiva. 
Igualmente son excepción legal a la carrera administrativa los servidores vinculados mediante nombramientos provisionales. Estos pretenden suplir de forma transitoria las vacancias temporales en empleos de carrera que no puedan ser provistos mediante encargo con funcionarios de carrera administrativa. A pesar de desempeñar cargos de carrera estos servidores no son vinculados mediante concurso ni adquieren las garantías correspondientes pues su vinculación se extiende por un máximo de seis meses prorrogables. Estas características particulares hacen que su estabilidad en el empleo solo pueda ser de carácter intermedio. Es decir, su desvinculación no podrá darse de forma arbitraria, pero tampoco deberá surtir un procedimiento determinado, solo se requerirá la motivación del acto administrativo.

Cuando se presenten casos en los cuales el ejercicio de la libertad contractual genere como consecuencia la vulneración de derechos fundamentales, esa libertad debe ceder. Así pues, sin perjuicio del tipo de nombramiento del servidor, si por su desvinculación peligran sus garantías constitucionales, el aparato estatal debe tomar toda medida que ampare dichos principios. Entre ellas, reforzar su estabilidad sin importar que hubiese ingresado al empleo público a través de un nombramiento provisional o mediante libre nombramiento y remoción.

\section{Protección constitucional de la eStabilidad laboral}

Conforme a la Constitución Política (1991) "el trabajo es un derecho y una obligación social y goza, en todas sus modalidades, de la especial protección del Estado" (art. 25). La especial protección que aquí se menciona se refiere a la obligación de garantizar el acceso a empleo y la estabilidad laboral a sujetos que por su condición particular necesitan ser cobijados de forma especial hasta tanto la situación fáctica que originó problemas sea superada (Daza, 2013).

La particularidad de una persona que cae en una situación como la descrita puede afectar de forma grave e irremediable principios constitucionales de orden fundamental, si no se le garantiza como mínimo la estabilidad en su empleo, conforme indica la Sentencia C-470/1997, que estableció con relación a la estabilidad laboral reforzada lo siguiente: 
Fernando Antonio Moreno González, Lina Stefania Arévalo Sanabria La prevalencia entre protección de derechos fundamentales o elementos de la naturaleza del cargo

En general el derecho a la estabilidad laboral consiste en la garantía que tiene todo trabajador a permanecer en el empleo y a obtener los correspondientes beneficios salariales y prestacionales, incluso contra la voluntad del patrono, si no existe una causa relevante que justifique el despido. [...] La protección tiene entonces que ser eficaz, por lo cual su regulación y aplicación está sometida a un control constitucional más estricto [...], por lo cual no es suficiente que el ordenamiento legal asegure unos ingresos monetarios a esas trabajadoras, sino que es necesario protegerles eficazmente su derecho efectivo a trabajar. (p. 15)

Ahora bien, la Corte Constitucional, en Sentencia T-320/2016, estableció las siguientes características de la estabilidad laboral reforzada:

i) El derecho a conservar el empleo; ii) a no ser despedido en razón de la situación de vulnerabilidad; iii) a permanecer en el empleo hasta que se requiera y siempre que no se configure una causal objetiva que conlleve la desvinculación del mismo [sic]; y iv) a que la autoridad laboral competente autorice el despido, con la previa verificación de la estructuración de la causal objetiva, no relacionada con la situación de vulnerabilidad del trabajador, que se aduce para dar por terminado el contrato laboral, so pena que, de no establecerse, el despido sea declarado ineficaz. (p. 17)

Esta protección especial cobija no solo a los empleados vinculados al sector privado, sino igualmente a aquellos que prestan sus servicios a entidades del Estado, es decir, los servidores públicos. Como es claro, dentro de su clasificación la forma de vinculación, la discrecionalidad de su retiro y su estabilidad laboral varían conforme al tipo de nombramiento que el servidor público tuviere. Si bien es cierto que el art. 125 superior indica que los cargos en la Administración deberán ser provistos por mérito, por eso gozan de la protección de garantías constitucionales y legales, se deberá tener en cuenta que cuando se presenten determinados grupos de funcionarios, sin importar que no hubiesen sido vinculados mediante el mérito, requerirán garantía de protección especial dada su condición particular.

Una situación así se genera al concurrir "una relación de dependencia intrínseca entre la permanencia en el empleo público y la garantía de sus derechos fundamentales" (C. 
Const. Sentencia T-156/2014, p. 14). La jurisprudencia colombiana ha identificado cuatro grupos poblacionales que, dada sus circunstancias particulares — sean estas físicas o psíquicas-, pueden verse inmersos en una disminución que afecte su estabilidad en el trabajo o la posibilidad de encontrar uno nuevo: prepensionado, madre o padre cabeza de familia, en situación de debilidad manifiesta o en estado de embarazo. Trátese de un servidor público o no, a cualquier persona en alguna de esas condiciones podrá reconocérsele estabilidad laboral reforzada hasta tanto sus derechos fundamentales dejen de estar en riesgo inminente de vulneración (Guarín y Aldana, 2016).

A continuación se esboza la estabilidad laboral reforzada en los servidores públicos vinculados mediante nombramiento provisional y libre nombramiento y remoción cuando se encuentran inmersos en alguno o varios de esos grupos de especial protección.

\section{Prepensionados}

Se entienden como prepensionados

aquellos servidores que cumplan con los requisitos para acceder a la pensión de jubilación o de vejez dentro de los tres años siguientes o, en otras palabras, aquellos a los que les falten tres años o menos para cumplir los requisitos que les permitirían acceder a la pensión de jubilación o vejez. (C. Const. Sentencia SU-897/2012, p. 46)

Es pertinente aclarar que la sola condición de prepensionado no es suficiente para gozar de un refuerzo en su estabilidad: es clave que se encuentren en riesgo derechos fundamentales como el mínimo vital o la seguridad social si se da la desvinculación del servidor.

La configuración de un perjuicio irremediable, conforme lo define la Sentencia T-225/1993, hace referencia a la existencia en primer lugar de un peligro inminente, es decir, la presencia de evidencia de dańo en corto plazo. Pero ello no indica que este deba estar consumado al momento de la desvinculación. "Lo inminente, pues, 
Fernando Antonio Moreno González, Lina Stefania Arévalo Sanabria La prevalencia entre protección de derechos fundamentales o elementos de la naturaleza del cargo

desarrolla la operación natural de las cosas, que tienden hacia un resultado cierto, a no ser que oportunamente se contenga el proceso iniciado" (C. Const. Sentencia T-225/1993, p. 14). Además, se debe dar la conjugación de urgencia y gravedad de la situación particular. Esta última implica la importancia jurídica de la afectación merecedora de una protección especial. Dada su envergadura la gravedad debe ser ante todo determinada o determinable. Así pues, como se manifestó en la Sentencia T-357/2016:

Es necesario evidenciar en el caso concreto que la desvinculación está poniendo en riesgo los derechos fundamentales del accionante, donde la edad del mismo [sic] es un indicador de la falta de probabilidades de integrarse al mercado laboral que debe apreciarse junto con el hecho de que el salario sea la única fuente de ingresos de este o, en todo caso, que los ingresos por otros conceptos sean insuficientes para garantizar una vida en condiciones dignas ante la ausencia del primero. (p. 14)

Ahora bien, como de forma específica se determina en la jurisprudencia analizada, el servidor nombrado bajo provisionalidad goza de estabilidad reforzada cuando es prepensionado, sin importar el carácter transitorio de su vínculo laboral, hasta que sea incluido en la respectiva nómina de pensionados. Sin el cumplimiento de lo anterior no puede ser ofertado el empleo de carrera ocupado bajo provisionalidad, $y$ "en caso de ser ofertado, su desvinculación no se puede efectuar antes de que este [el funcionario provisional] se encuentre en nómina de pensionados" (C. Const. Sentencia T-156/2014, p. 24).

El derecho a la estabilidad laboral reforzada que de esta condición se deriva no permite la desvinculación del servicio por el simple vencimiento del plazo pactado, de darse este. Se deberá ordenar el reintegro de aquellos provisionales próximos a pensionarse siempre que dicha desvinculación signifique una afectación de sus derechos fundamentales. Por lo anterior no puede desconocerse que, conforme a la Sentencia T-800/1998, los empleados públicos provisionales gozan de una estabilidad laboral intermedia, lo que implica como requisito del acto administrativo que los desvincula la motivación de este. Tal particularidad no se desdibuja por el solo hecho de verse inmersos en situación vulnerante (Saidiza y Carvajal, 2016). 
A contrario sensu, dada la especificidad transitoria de su nombramiento, se deberá realizar un test de proporcionalidad (figura 1) en cada caso concreto, que determine el nivel de afectación del núcleo esencial de cada uno de los extremos, así:

Figura 1. Eventual test de proporcionalidad en provisionales

\begin{tabular}{ccc}
\hline P1 & vs. & P2 \\
Cumplimiento \\
del deber legal & Vida \\
& Mínimo vital \\
Salud \\
& Seguridad \\
& Otros... \\
\hline & \\
\hline
\end{tabular}

Finalidad

Idoneidad

Necesidad

Proporcionalidad

Fuente: elaboración propia atendiendo a los criterios propuestos para el test de proporcionalidad expuesto en C. Const. Sentencia C-470/2011.

Como se determinó en la Sentencia T-326/2014 con relación a la idoneidad del test de proporcionalidad, cuando se pretenda la desvinculación de un servidor nombrado en provisionalidad se deberá tener en cuenta

i) la necesidad de que las autoridades del Estado interpreten las normas de forma razonable, proporcionada y compatible con los derechos fundamentales de los afectados, y ii) la obligación de que estas mismas autoridades hagan una evaluación objetiva de las circunstancias del caso, diferente a una adjudicación aleatoria, en la cual se determine si es posible proteger concomitantemente los derechos del prepensionado y del aspirante. (p. 28) 
Fernando Antonio Moreno González, Lina Stefania Arévalo Sanabria La prevalencia entre protección de derechos fundamentales o elementos de la naturaleza del cargo

Así pues, no basta con la culminación del tiempo estipulado o la existencia de la lista de elegibles para dicho empleo para que se dé la desvinculación del provisional: la Administración y el órgano judicial deberán garantizar el cumplimiento de obligaciones concernientes a la protección de los derechos fundamentales de quien se encuentre bajo el supuesto de prepensionado.

Cosa contraria a lo anterior ocurre con aquellos servidores vinculados mediante libre nombramiento y remoción, que por regla general no gozan de las garantías constitucionales y jurisprudenciales de estabilidad reforzada en caso de encontrarse en la situación de prepensionados. La jurisprudencia constitucional con relación a los servidores públicos de libre nombramiento y remoción ha tenido criterios variantes entre una sentencia y otra. Así pues, se estableció en la Sentencia T-862/2009 que, sin perjuicio de la estabilidad precaria que recae sobre este tipo de funcionarios, esta debía ser elevada al estándar de reforzada cuando se adelantaran procesos de reestructuración administrativa, es decir, cuando aquellos estuvieran inmersos bajo el retén social (Garzón, 2013).

El programa de renovación de la administración pública, al que hace referencia la sentencia anterior, se rigió por las disposiciones de la Ley 790 de 2002, cuyo objetivo fue

renovar y modernizar la estructura de la rama Ejecutiva del orden nacional, con la finalidad de garantizar, dentro de un marco de sostenibilidad financiera de la Nación, un adecuado cumplimiento de los fines del Estado con celeridad e inmediación en la atención de las necesidades de los ciudadanos. (art. 1)

Cuando ello implica reestructuración de la planta de personal los servidores vinculados a la entidad correspondiente — bajo los presupuestos de igualdad, seguridad social y dignidad - adquieren un estatus equivalente entre sí, sin importar su forma de vinculación. De esta forma, se estableció en la Sentencia T-862/2009 que

la administración está obligada a adoptar medidas de diferenciación positiva a favor del servidor público que pueda llegar a ser considerado como sujeto de 
especial protección y que resulte afectado con la supresión del cargo del que es titular, independientemente de la naturaleza de su nombramiento. (p. 12)

Continuando con la línea anterior, la Sentencia T-802/2012 dispuso que cuando un funcionario se encuentre bajo la figura de prepension no podrá recibir una diferenciación en la garantía de derechos pues eso constituiría una discriminación injustificada en la protección de sus derechos fundamentales:

Los empleados públicos de libre nombramiento y remoción aunque gozan de una estabilidad laboral precaria, deben tener un tratamiento igualitario a los demás tipos de servidores cuando reúnan los requerimientos para acceder a la protección especial consagrada en el "retén social”. (p. 16)

Así pues,

no será constitucionalmente admisible la desvinculación que de dicho funcionario se haga, y se presumirá su capacidad para desarrollar sus labores con confianza, hasta tanto este no adquiera su jubilación o sea declarado insubsistente por existencia de causa justificativa que, en todo caso, deberá estar relacionada estrictamente con su desempeño. (C. Const. Sentencia T-685/2016, p. 26)

Sin embargo, no todo funcionario de libre nombramiento y remoción prepensionado será cobijado con la protección pues no podrá ser de alta dirección. Entiéndase este como aquel destinado al desarrollo de políticas públicas de su nominador —un funcionario de elección popular_- Por ello, el amparo recaerá únicamente en aquellos que ocupen cargos directivos dentro de las entidades (Humbarita, 2015).

Como se evidenció previamente, los funcionarios vinculados mediante libre nombramiento y remoción gozan de refuerzo en su estabilidad cuando son prepensionados, si se encuentran bajo el margen del retén social, pero si esta situación particular no se presenta, no serán acreedores de tal protección. Así se manifestó en la Sentencia T-460/2017, en la cual se le niega el amparo al solicitante al no verse inmerso en un proceso de reestructuración administrativa, por lo cual no puede 
Fernando Antonio Moreno González, Lina Stefania Arévalo Sanabria La prevalencia entre protección de derechos fundamentales o elementos de la naturaleza del cargo

gozar de la protección que se otorga bajo el retén social. Al no existir tal situación no opera la garantía constitucional pues de hacerlo podría afectar las funciones del nominador —él mismo una excepción constitucional a la carrera administrativa-.

De este modo, es viable en tales casos la declaratoria de insubsistencia, toda vez que el nominador "tiene plena autonomía para nombrar a las personas que considere idóneas para el desarrollo de funciones de dirección, manejo y confianza" (C. Const. Sentencia T-460/2017, p. 20). Ha sido claro, pues, que la figura de prepensionado es distinta a la de reten social, y por lo tanto los funcionarios inmersos en cada una de ellas reciben un trato diferenciado, en especial cuando han sido vinculados mediante libre nombramiento y remoción.

Por otro lado, es menester que no solo se cumpla con el número de semanas de cotización correspondiente, sino, en igual medida, con la edad para acceder a su derecho pensional. En ese sentido se pronunció la Corte Constitucional en la Sentencia SU-003/2018:

Cuando el único requisito faltante para acceder a la pensión de vejez es el de la edad, dado que se acredita el cumplimiento del número mínimo de semanas de cotización, en caso de desvinculación, no se frustra el acceso a la pensión de vejez, de allí que no haya lugar a considerar que la persona sea beneficiaria del fuero de estabilidad laboral reforzada de prepensionable, dado que el requisito faltante, relativo a la edad, puede ser cumplido de manera posterior, con o sin vinculación laboral vigente. (p. 22)

Lo anterior ocurre al establecer que no se configura un riesgo de no consolidación del acceso a la pensión de vejez ya que, al existir como requisito faltante el cumplimiento de la edad, este puede alcanzarse a pesar de la desvinculación. Así pues, desvirtuado el fuero de estabilidad en tales casos, la sentencia SU-003/2018 reiteró que, por la confianza inherente de los cargos de libre nombramiento y remoción, no es procedente la estabilidad distinta a la discrecionalidad de su nominador, excepto en aquellos casos inmersos bajo el considerando del retén social (González, 2014). 


\section{Madres o padres cabeza de familia}

Previo análisis de esta protección para servidores vinculados a través de provisionalidad o libre nombramiento y remoción debe determinarse cuándo se considera jurisprudencialmente que una persona es cabeza de familia. Así pues, en primer lugar es importante resaltar que el antecedente normativo más próximo que determinó dicha condición como merecedora de una protección especial fue la Ley 790 de 2002, citada con anterioridad, la cual en su art. 12 señala como sujetos de protección a "las madres cabeza de familia sin alternativa económica" cuando la Administración estuviese inmersa en un proceso de reestructuración. De esta forma, ante la necesidad de definir tal condición el Decreto 190 de 2003 indicó que madre cabeza de familia es la

mujer con hijos menores de 18 años de edad, biológicos o adoptivos, o hijos inválidos que dependan económicamente y de manera exclusiva de ellas [sic], y cuyo ingreso familiar corresponde únicamente al salario que devenga del organismo o entidad pública a la cual se encuentra vinculada. (art. 1)

Como es de esperarse, el solo hecho de ser madre cabeza de familia no es calidad suficiente para gozar de una estabilidad laboral reforzada. Adicionalmente deben cumplirse una serie de factores para su procedencia, que se determinaron en la Sentencia SU-388/2005 así:

i) Que se tenga a cargo la responsabilidad de hijos menores o de otras personas incapacitadas para trabajar; ii) que esa responsabilidad sea de carácter permanente; iii) no solo la ausencia permanente o abandono del hogar por parte de la pareja, sino que aquella se sustraiga del cumplimiento de sus obligaciones como padre; iv) o bien que la pareja no asuma la responsabilidad que le corresponde y ello obedezca a un motivo verdaderamente poderoso como la incapacidad física, sensorial, síquica o mental o, como es obvio, la muerte; v) por último, que haya una deficiencia sustancial de ayuda de los demás miembros de la familia, lo cual significa la responsabilidad solitaria de la madre para sostener el hogar. (p. 21) 
Fernando Antonio Moreno González, Lina Stefania Arévalo Sanabria La prevalencia entre protección de derechos fundamentales o elementos de la naturaleza del cargo

Conforme se determinó en la normatividad de la época, la protección recaía de forma exclusiva en las mujeres, lo que excluía únicamente por razón de su sexo al hombre que se encontrara en la misma situación. Así pues, en aras de dirigir la protección "a quienes se ven afectados con la desvinculación laboral de aquella persona que en solitario asume la carga de suplir las necesidades del hogar" (C. Const. Sentencia T-400/2014, p. 23), y no de forma exclusiva al sexo femenino, se estructuró en la Sentencia SU-389/2005, el panorama del hombre que no solo provee los bienes de consumo, sino que asume un rol de cuidado, protección y responsabilidad en el hogar. De ese modo, cuando el hombre cabeza de familia desee ser cobijado con garantía constitucional de estabilidad reforzada en su empleo deberá demostrar:

i) Que sus hijos propios, menores o mayores discapacitados, estén a su cuidado, que vivan con él, dependan económicamente de él y que realmente sea una persona que les brinda el cuidado y el amor que los niños requieran para un adecuado desarrollo y crecimiento; que sus obligaciones de apoyo, cuidado y manutención sean efectivamente asumidas y cumplidas, pues se descarta todo tipo de procesos judiciales y demandas que se sigan contra los trabajadores por inasistencia de tales compromisos.

ii) Que no tenga alternativa económica, es decir, que se trate de una persona que tiene el cuidado y la manutención exclusiva de los niños y que, en el evento de vivir con su esposa o compañera, esta se encuentre incapacitada física, mentalmente o moralmente, sea de la tercera edad, o su presencia resulte totalmente indispensable en la atención de hijos menores enfermos, discapacitados o que médicamente requieran la presencia de la madre. (p. 27)

Ahora bien, además de los requisitos exigidos por la jurisprudencia para ser reconocida la condición de madre o padre de familia, es obligación contemplada en la Ley 82 de 1993, modificada por la Ley 1232 de 2008, que

esta condición y la cesación de la misma [sic], desde el momento en que ocurra el respectivo evento, deberá ser declarada por la mujer cabeza de familia de bajos ingresos ante notario, expresando las circunstancias básicas de su caso 
y sin que por este concepto se causen emolumentos notariales a su cargo. ${ }^{1}$ (art. 2)

La protección no recae de forma principal en la garantía constitucional de los derechos fundamentales del servidor madre o padre, sino en la protección de aquellos que se encuentran a cargo del sujeto principal: son ellos quienes se ven afectados de forma directa por la desvinculación "de aquella persona que en solitario asume la carga de suplir las necesidades del hogar” (C. Const. T-400/2014, p. 23). Por eso es importante resaltar la reiteración jurisprudencial sobre la necesidad de que el servidor sea el único responsable de la manutención y cuidado de quienes se encuentran a su cargo.

La Corte Constitucional enfatiza en que se debe demostrar que los hijos dependen absolutamente de la persona cuyo empleo está en riesgo, ya sea por la ausencia física del cónyuge o por su imposibilidad de colaboración. En el primer caso la carga probatoria recae sobre el servidor que pretende reforzar su estabilidad, quien deberá comprobar mediante mecanismos jurídicos idóneos el incumplimiento del otro cónyuge, entiéndase esto como acciones judiciales tendientes a hacer responsable a este de su obligación legal. Por lo tanto, el estado civil de la persona cabeza de familia resulta irrelevante a la hora de probar la dependencia absoluta. En el segundo caso, la imposibilidad de colaboración, debe entenderse como el impedimento físico o mental del cónyuge para ayudar en la satisfacción de las necesidades básicas del hogar. Igualmente, se "ha aclarado que una mujer no deja de ser madre cabeza de familia por el hecho de que las personas a su cargo cumplan la mayoría de edad" (C. Const. Sentencia T-420/2017, p. 16). Pues bien, en tales casos debe comprobarse que los dependientes mayores de edad no cuentan con la posibilidad de trabajar por sus condiciones fácticas particulares.

De la misma forma, es claro que el núcleo familiar no es homogéneo en la sociedad pues las familias presentan distintos tipos de unión y conformación. Por lo tanto, es menester que el ordenamiento jurídico se acople a tales realidades sociales: "En este

1 La expresión "madre cabeza de familia" no puede entenderse como discriminatoria del padre cabeza de familia. A contrario sensu, este se encuentra en la misma obligación legal que aquella. 
Fernando Antonio Moreno González, Lina Stefania Arévalo Sanabria La prevalencia entre protección de derechos fundamentales o elementos de la naturaleza del cargo

orden de ideas, el vínculo familiar puede estar conformado por una madre soltera y su hijo o hija, e incluso por un padre y sus descendientes, igualmente se puede dar entre hermanos, hermanas, primos, nietos y abuelos" (C. Const. Sentencia T-345/2015, p. 22). Así, la estabilidad en el empleo de aquel que demuestre tal condición se fundamenta en la protección constitucional según la cual

la familia es el núcleo fundamental de la sociedad. Se constituye por vínculos naturales o jurídicos, por la decisión libre de un hombre y una mujer de contraer matrimonio o por la voluntad responsable de conformarla. El Estado y la sociedad garantizan la protección integral de la familia. (art. 42)

Sin perjuicio de lo anterior, se ha establecido que, a pesar de la existencia de los criterios expuestos previamente, es requisito sine qua non que el funcionario hubiese advertido con anterioridad a la Administración de su situación particular, tal como se indica en la Sentencia T-420/2017:

Además de la condición de sujeto de especial protección, debe demostrarse que se dio aviso oportuno a la entidad encargada de hacer efectivo el contenido de dicha protección, esto con el fin de demostrar que se emplearon los medios que el titular tenía a su alcance para buscar el reconocimiento de la garantía iusfundamental. (p. 16)

La protección constitucional concerniente al reforzamiento de la estabilidad del servidor permanecerá hasta tanto ocurra alguna de las siguientes situaciones:

i) [Que] se termine el proceso de liquidación de la institución; ii) [que los protegidos] pierdan las condiciones establecidas para ser titulares de dicha salvaguarda; o iii) [que] incurran en hechos que funden la terminación del contrato en una justa causa o que constituyan causal de destitución del cargo en el caso de las empleadas públicas. (C. Const. Sentencia T-420/2017, p. 18)

Así pues, jurisprudencialmente se ha encontrado la posibilidad de protección para servidores públicos nombrados en provisionalidad cuando se encuentran bajo este supuesto, pero de forma expresa la jurisprudencia no se ha manifestado con 
relación a los servidores de libre nombramiento y remoción. No obstante, sí se hace especial énfasis en la protección originaria mediante el retén social. Por lo tanto, se podría determinar que si se presenta una situación en la cual un servidor de libre nombramiento cumple con los criterios aquí expuestos y adicional a ello hace parte de un proceso de reestructuración de la Administración, podría ser protegido hasta tanto se culmine dicho proceso o desaparezcan las situaciones específicas que lo hacen objeto de amparo.

\section{Personas con debilidad manifiesta}

Se entiende por debilidad manifiesta la situación de una persona sujeta a una afectación en su salud que dificulta el óptimo desempeño de sus funciones como empleada. Dicha afectación puede ser física o mental, pero dada su especialidad puede generar discriminación por parte del empleador. Así, al existir una situación que puede poner en riesgo el pleno desarrollo y goce de sus derechos fundamentales, se debe cobijar al servidor afectado con una estabilidad reforzada que no permita su desvinculación por cuenta de su situación particular.

La anterior protección se origina en la Constitución Política de 1991, la cual especifica que "el Estado protegerá especialmente a aquellas personas que, por su condición económica, física o mental, se encuentren en circunstancia de debilidad manifiesta" (art. 13). En concordancia con lo anterior, el art. 47 establece que "el Estado adelantará una política de previsión, rehabilitación e integración social para los disminuidos físicos, sensoriales y psíquicos, a quienes se prestará la atención especializada que requieran". Todo ello igualmente para garantizar el cumplimiento de la obligación consignada en el art. 54: "El Estado debe propiciar la ubicación laboral de las personas en edad de trabajar y garantizar a los minusválidos el derecho a un trabajo acorde con sus condiciones de salud". La normatividad constitucional se ve reforzada tras la ratificación por parte de Colombia de la Convención Interamericana para la Eliminación de Todas las Formas de Discriminación y la Convención de la Naciones Unidas sobre los Derechos de las Personas con Discapacidad, normativas internacionales tendientes a proteger los derechos de las personas con discapacidad a trabajar en igualdad de condiciones con las demás. De la misma forma, la Asamblea General de la ONU (1994), conforme a la Resolución 48/96 estableció: 
Fernando Antonio Moreno González, Lina Stefania Arévalo Sanabria La prevalencia entre protección de derechos fundamentales o elementos de la naturaleza del cargo

\begin{abstract}
Con la palabra discapacidad se resume el gran número de diferentes limitaciones funcionales que se registran en las poblaciones de todos los países del mundo. La discapacidad puede revestir la forma de una deficiencia física, intelectual o sensorial, una dolencia que requiera atención médica o una enfermedad mental. Tales deficiencias, dolencias o enfermedades pueden ser de carácter permanente o transitorio.
\end{abstract}

Esta protección especial pretende garantizar a la persona en situación de discapacidad el acceso al empleo de forma libre y permanente, y la conservación de este, sin que su circunstancia particular sea motor para su eventual desvinculación. Ahora bien, la debilidad puede originarse de forma previa al empleo o en el transcurso de este, razón por la cual la jurisprudencia constitucional se ha encargado de salvaguardar las distintas posibilidades en las cuales se puede ver inmerso el servidor catalogado como sujeto de especial protección:

Están amparadas por la protección prevista en el artículo 26 de la Ley 361 de 1997, no solamente aquellas personas que tienen la condición de discapacitadas, de acuerdo con la calificación efectuada por los organismos competentes, sino también, quienes se encuentran en una situación de debilidad manifiesta, ya sea por acaecimiento de un evento que afecta su salud, o de una limitación física, sin importar si esta tiene el carácter de accidente, enfermedad profesional, o enfermedad común, ni si es de carácter transitorio o permanente. (C. Const. Sentencia T-019/2011, p. 42)

Debe resaltarse que, al tratarse de funcionarios con afecciones de salud, "la continuidad en la atención médica cobra vertebral trascendencia como quiera que desatender dicho principio compromete peligrosamente la eficacia en el goce de sus derechos fundamentales" (C. Const. Sentencia T-029/2016, p. 37). Es decir, los servicios médicos de aquellos deben ser suministrados de forma inmediata, preferencial y prioritaria. Pero en caso de una desvinculación puede darse una interrupción de tratamiento o medicación, lo que puede generar daños irremediables en la persona. Así pues, no basta con la configuración de los requisitos jurídicos normales para dicha desvinculación. Tal como se afirmó en la Sentencia T-373/2017, es claro que "estas personas no tienen un derecho a permanecer de manera indefinida en el 
cargo, pues este debe proveerse por medio de un concurso de méritos, [pero] sí debe otorgárseles un trato preferencial como acción afirmativa” (p. 12). Entiéndase acción afirmativa como aquella

que pretende establecer políticas que dan a un determinado grupo social, étnico, minoritario o que históricamente haya sufrido discriminación a causa de injusticias sociales, un trato preferencial en el acceso o distribución de ciertos recursos o servicios así como acceso a determinados bienes. (Filac, s. f., p. 1)

Es claro que el nombramiento de estos servidores es de carácter transitorio y, por lo tanto, a pesar de su situación de vulnerabilidad, estos no pueden permanecer en el empleo de forma indefinida e ininterrumpida. Pero sí es obligación de la Administración tener especial cuidado en cuanto su manejo, movilidad y desvinculación laboral pues corre el riesgo de lesionar sus derechos fundamentales. Así pues, la carga probatoria recae sobre la Administración, que debe demostrar la existencia de una causal objetiva para la desvinculación del funcionario vulnerable, tal como lo manifestó la Corte en su momento:

La Corte Constitucional, con base en las normas citadas precedentemente, ha señalado que las personas con limitaciones físicas, sensoriales o síquicas tienen derecho a una estabilidad laboral reforzada, que se concreta en la prerrogativa de permanecer en el empleo y de gozar de cierta seguridad de continuidad, mientras no se configure una causal objetiva que justifique su desvinculación, siendo una de sus mayores implicaciones la inversión de la carga de la prueba, de suerte que se constituye una presunción de discriminación sobre todos los actos que tengan por finalidad desmejorar las condiciones laborales de los trabajadores con alguna discapacidad, al punto que corresponde al empleador desvirtuar la presunción y demostrar que tales actuaciones atienden a una causal objetiva. (Sentencia T-605/2013, p. 14)

Dicha protección surge del principio de solidaridad, el cual indica que el Estado debe velar por la protección de quienes se encuentran en condición de debilidad. "Lo anterior por cuanto las normas constitucionales no se interpretan únicamente 
Fernando Antonio Moreno González, Lina Stefania Arévalo Sanabria La prevalencia entre protección de derechos fundamentales o elementos de la naturaleza del cargo

de manera descriptiva, sino que son mandatos prescriptivos de aplicación inmediata, de tal forma que intervienen en las relaciones de los asociados y de estos con el Estado” (C. Const. Sentencia T-490/2010, p. 14). Así pues, sin perjuicio de la vinculación del servidor prevalece el resguardo de sus derechos fundamentales pues en caso contrario se presentaría una abierta discriminación. Sin embargo, como se manifestó previamente, si la Administración cuenta con una causa real que permita la desvinculación, podrá hacerla efectiva, siempre que logre demostrar la existencia de dicha objetividad, la cual debe ser distinta al vencimiento del plazo pactado.

Ahora bien, la estabilidad laboral reforzada con relación a la debilidad manifiesta en nombramientos provisionales se ha clarificado en repetidas providencias constitucionales citadas en el presente aparte. Se ha otorgado así la protección, aun cuando exista un funcionario que por merito deba tener acceso al mismo empleo. Cosa distinta se evidencia nuevamente con los funcionarios vinculados mediante libre nombramiento y remoción, en los cuales la jurisprudencia no hace énfasis. Sin embargo, como la disminución física o la afectación psicológica hacen parte del grupo poblacional sujeto de protección especial según la Ley 790 de 2002, continúa abierta la posibilidad de que tal grupo goce de un reforzamiento en su estabilidad, a pesar del carácter discrecional de su desvinculación.

Finalmente, la providencia T-353/2016 resaltó que el reforzamiento de la estabilidad en el empleo no recae únicamente en la no desvinculación del servidor sin causa objetiva, sino también en la reubicación del puesto de trabajo: debe ofrecerse uno en el cual se pueda potencializar la capacidad laboral del funcionario sin perjuicio de su condición particular (Guarín, 2013).

\section{Mujeres en estado de embarazo}

Conforme obra en la Constitución Política de 1991, la mujer "durante el embarazo y después del parto gozará de especial asistencia y protección del Estado" (art. 43). La protección en cabeza del Estado abarca todas las esferas de la vida de la mujer en proceso de gestación y lactancia. Una de ellas, la garantía del goce efectivo de su derecho al empleo y a no ser desvinculada de este por razón de su estado. Así pues, 
la OIT en su Recomendación 95 estableció que se debe garantizar la protección en el empleo en

el periodo antes y después del parto durante el cual sea ilegal para el empleador despedir a una mujer [...]. Motivos tales como una falta grave de la mujer empleada, la cesación de las actividades de la empresa donde esté ocupada o la terminación de su contrato de trabajo podrán ser considerados, por la legislación nacional, como causas justas para el despido [...]. Durante la ausencia legal, antes y después del parto, los derechos de antigüedad de la mujer deberían ser salvaguardados, así como su derecho a ocupar nuevamente su antiguo trabajo o un trabajo equivalente retribuido con la misma tasa. (1952, art. 4)

Si bien, "todos los trabajadores tienen un derecho general a la estabilidad en el empleo, existen casos en que este derecho es aún más fuerte, por lo cual en tales eventos cabe hablar de un derecho constitucional a una estabilidad laboral reforzada" (C. Const. Sentencia C-470/1997, p. 13). Dicha protección no solo pretende cobijar a la mujer que por su situación particular puede ver afectado su derecho a la salud, el mínimo vital, la seguridad social, entre otros, sino que se extiende igualmente al nasciturus, al que garantiza el primer desarrollo de su vida en el vientre o fuera de este de forma plena.

Esta "es una medida protectora básica que cualquier sociedad acoge, acorde con el principio de la dignidad humana" (C. Const. Sentencia T-238/2015, p. 17). De esta forma, el legislador decidió proteger el vínculo laboral de las servidoras provisionales dando origen a la Ley 909 de 2004, la cual indicó que "no procederá el retiro de una funcionaria con nombramiento provisional $[. .$.$] mientras se encuentre en estado de$ embarazo o en licencia de maternidad" (art. 51).

Para que se origine una protección efectiva e integral a la mujer embarazada esta debió comunicar antes de la desvinculación su estado de gestación. De esta forma se presumirá que tal desvinculación ha sido por razón de dicho estado, lo que constituye una discriminación de orden sexual. Por otra parte, la comunicación 
Fernando Antonio Moreno González, Lina Stefania Arévalo Sanabria La prevalencia entre protección de derechos fundamentales o elementos de la naturaleza del cargo

podrá ser una notificación directa, un hecho notorio ${ }^{2}$ o la noticia de un tercero, no siendo indispensable la existencia de un documento que constituya plena prueba del conocimiento del empleador. Conforme a la Sentencia SU-070/2013, no generar tal comunicación

dará lugar a una protección más débil, basada en el principio de solidaridad y en la garantía de estabilidad en el trabajo durante el embarazo y la lactancia, como un medio para asegurar un salario o un ingreso económico ala madrey como garantía de los derechos del recién nacido. (p. 55)

Así pues, la Corte Constitucional indicó que carece de toda eficacia la desvinculación de una funcionaria embarazada que se dé sin causa objetiva ni previa autorización del Ministerio del Trabajo, el cual tendrá la potestad de verificar la real existencia de tal causa. Sin perjuicio de lo anterior, de darse esta será obligatorio el pago de las prestaciones hasta tanto la mujer dé a luz y se cumpla el periodo de lactancia posterior. Se precisó como regla jurisprudencial que

procede la protección reforzada derivada de la maternidad, luego la adopción de medidas protectoras en caso de cesación de la alternativa laboral, cuando se demuestre, sin alguna otra exigencia adicional: a) la existencia de una relación laboral o de prestación y b) que la mujer se encuentre en estado de embarazo o dentro de los tres meses siguiente al parto, en vigencia de dicha relación laboral o de prestación. (Sentencia SU-070/2013, p. 62)

De esta forma, no podrá entenderse como causal objetiva de desvinculación el vencimiento del plazo pactado en el nombramiento de la servidora o la discrecionalidad de su empleo pues "las causales de terminación desprendidas de regulaciones específicas deben ser interpretadas a la luz de la Constitución y no pueden constituir razones válidas para eludir la protección de la maternidad" (C. Const. Sentencia T-102/2016, p. 29). Por ello, se deben adoptar todas las

2 Conforme a la Sentencia SU-070/2013, este se constituye cuando se infiere el estado de embarazo de la funcionaria, es decir, ante la existencia de cambios físicos, el conocimiento público del estado de gestación o la solicitud de permisos o presentación de incapacidades con ocasión de dicho estado. 
medidas de protección necesarias para hacer prevalecer los derechos fundamentales de la mujer y de la persona que está por nacer.

Esta garantía de estabilidad reforzada en el empleo no solo cobija a las madres gestantes, sino, con igual alcance, a las madres adoptantes. La jurisprudencia determinó esta extensión de conformidad con pilares constitucionales y legales para proteger a las familias constituidas por vínculos civiles. Lo anterior tuvo su origen en la Ley 24 de 1986, la cual estableció que

todas las provisiones y garantías establecidas en el presente capítulo para la madre biológica se hacen extensivas, en los mismos términos y en cuanto fuere procedente, para la madre adoptante del menor de 7 años de edad ${ }^{3}$, asimilando a la fecha del parto la de la entrega oficial del menor que se adopta. (art. 1. Énfasis añadido)

Solo en 1988, mediante la Ley 69, se extendió tal protección a las empleadas del sector público, en los mismos términos y condiciones establecidos previamente por la Ley 24 de 1986. La protección durará todo el tiempo que dure el estado de gestación, y se extenderá hasta la semana 18 del recién nacido, término establecido en la Ley 1822 de 2017. Dicha norma igualmente reafirma la extensión de la protección especial a la madre adoptante o al padre que quede a cargo del recién nacido. La importancia de reconocer la misma protección a la madre adoptante recae en que ella, igual que la madre biológica, necesita previa preparación a la llegada del menor, y a su vez los momentos posteriores al parto o la entrega son indispensables para reforzar los vínculos y la protección que se crea alrededor del nuevo miembro de la familia. De esta forma, en la Sentencia T-499A/2017 la Corte manifestó:

La madre biológica se prepara durante el embarazo para recibir al nuevo integrante de la familia y necesita recuperarse físicamente del parto y estar

3 La Sentencia C-543/2010 declaró inexequible la expresión "del menor de siete (7) años de edad", al considerar que dicha limitación era contraria a la Constitución: al mandato de igualdad que establece el art. 13; al principio que ordena reconocer a todos los hijos los mismos derechos sin importar la forma como hayan llegado a la familia, estipulado en el art. 42, y a la protección prevalente de la nińez que establece el art. 44. 
Fernando Antonio Moreno González, Lina Stefania Arévalo Sanabria La prevalencia entre protección de derechos fundamentales o elementos de la naturaleza del cargo

al lado de su bebé para cuidarlo en sus primeros meses de vida, la madre adoptante debe hacer lo propio una vez se le ha confirmado la entrega del niño, con el propósito de garantizar que a su llegada cuente con los elementos — tanto materiales como emocionales_ que posibiliten la construcción con el hijo adoptivo de los lazos que reforzarán las relaciones maternas y garantizarán la integración y adaptación del niño al nuevo núcleo familiar. (p. 19)

La protección de la madre adoptante surge cuando esta tiene plena certeza sobre la entrega del menor. Es decir,

la comunicación a los solicitantes de la aprobación de su solicitud y la asignación del niño, niña o adolescente por parte del Comité de Adopciones resulta asimilable a la noticia del embarazo y, por tanto, debe gozar de la debida protección constitucional a la maternidad. (C. Const. Sentencia T-499A/2017, p. 36)

La protección a la maternidad se presenta sin importar el tipo de vinculación laboral de la funcionaria. Tanto la normatividad como la jurisprudencia han protegido a la servidora vinculada provisionalmente, y dicha protección también se ha extendido a aquellas funcionarias vinculadas a través de libre nombramiento y remoción. Tal como obra en la Sentencia SU-070/2013, se distinguen en dicho caso dos hipótesis (García, 2013). La primera de ellas determina que si el nominador conoce del estado de embarazo de la funcionaria antes de la declaratoria de insubsistencia, procederá la protección constitucional, lo que origina de esta forma el reintegro y el pago de los salarios y prestaciones dejados de percibir. A contrario sensu, la segunda hipótesis indica que si el nominador no tenía conocimiento de dicha situación solo aplicará el pago de cotizaciones requeridas para obtener la licencia de maternidad.

Así, se logra determinar que la protección a la maternidad no solo recae en la servidora en estado de gravidez, dada su vulnerabilidad, o en la mujer adoptante, sino también en el no nacido o en el menor que se recibirá con posterioridad. Además se protegen todas las esferas de la vida de la funcionaria, sin importar su vinculación, la duración del plazo pactado o la discrecionalidad de su remoción (Vargas y Bracchi, 2016). 


\section{Conclusiones}

Se logra determinar, bajo el análisis de la jurisprudencia recolectada, que la protección a la estabilidad laboral reforzada para aquellos servidores que son excepción a la carrera administrativa es variable. La jurisprudencia ha determinado para cada una de las situaciones de protección reglas de unificación comunes a todos los tipos de vinculación, siempre rigiéndose por los principios de proporcionalidad y necesidad de las medidas a tomar por parte de la Administración.

Es claro que los funcionarios vinculados mediante nombramiento provisional gozan de las mismas garantías que un servidor público de carrera en cuanto se refiere a la garantía de protección de sus derechos fundamentales, al menos cuando se logra determinar que el sujeto debe ser amparado bajo la estabilidad laboral, sin perjuicio de que su nombramiento sea de carácter transitorio y se dé el vencimiento del plazo pactado.

Por otra parte, los funcionarios vinculados mediante libre nombramiento y remoción carecen de protección constitucional por regla general. Esta aparece cuando se trata de casos específicos inmersos bajo el retén social y únicamente de forma amplia y extensiva cuando ampara a mujeres en estado de embarazo. De no presentarse una de estas particularidades, la jurisprudencia no cobija a dichos servidores pues siempre ha recalcado la confianza personal que recae en su nombramiento y la importancia de la discrecionalidad de este.

Así, la estabilidad laboral reforzada pretende garantizar la protección efectiva de los derechos de aquellos servidores que por sus condiciones particulares pueden ser víctimas de discriminación al ingreso y durante la ejecución de su empleo. Sin embargo, el hecho de encontrase inmerso en alguna de las definiciones de protección no implica que se tenga derecho inmediato al goce de esta pues deben configurarse circunstancias materiales adicionales que evidencien un riesgo inminente de vulneración. Así pues, dicha protección no es absoluta pues de presentarse una causal objetiva de desvinculación, esta podrá darse sin que ello se considere una violación a derechos fundamentales del servidor. 
Fernando Antonio Moreno González, Lina Stefania Arévalo Sanabria La prevalencia entre protección de derechos fundamentales o elementos de la naturaleza del cargo

La estabilidad laboral pretende garantizar la no vulneración de los derechos fundamentales de aquellos que están al servicio de la administración pública prohibiendo su desvinculación sin la causal de una circunstancia objetiva. Dicha protección se genera en aras de evitar la discriminación de los referidos funcionarios por sus circunstancias fácticas particulares.

Los servidores públicos vinculados mediante un nombramiento provisional, si bien por la naturaleza transitoria de su empleo no gozan de todas las garantías legales de un funcionario de carrera administrativa, son ampliamente cobijados por la Corte Constitucional ante la violación de sus derechos fundamentales. Es decir, a pesar de que su estabilidad sea de carácter intermedio, cuando se trate de las circunstancias ya expresadas su protección adquiere el carácter de reforzada.

Cuando se trate de nombramientos ordinarios, estos funcionarios no gozan de estabilidad laboral, excepto cuando se evidencia que se trata de una servidora en estado de gestación. Salvo esta última situación, ante tales nombramientos prima la discrecionalidad del nominador, en aras de continuar con la prestación de un buen servicio público, sobre la vulneración de derechos fundamentales.

\section{REFERENCIAS}

Asamblea General de la ONU (4 de marzo de 1994). Resolución 48/96. Normas uniformes sobre la igualdad de oportunidades para las personas con discapacidad.

Corte Constitucional. Sentencia T-225 (15 de junio de 1993). M. P. Vladimiro Naranjo Mesa.

Corte Constitucional. Sentencia C-470 (25 de septiembre de 1997). M. P. Alejandro Martínez Caballero.

Corte Constitucional. Sentencia T-800 (14 de diciembre de 1998). M. P. Vladimiro Naranjo Mesa. 
Corte Constitucional. Sentencia SU-388 (13 de abril de 2005). M. P. Clara Inés Vargas Hernández.

Corte Constitucional. Sentencia SU-389 (13 de abril de 2005). M. P. Jaime Araújo Rentería.

Corte Constitucional. Sentencia T-862 (27 de noviembre de 2009). M. P. Jorge Iván Palacio Palacio.

Corte Constitucional. Sentencia T-490 (16 de junio de 2010). M. P. Jorge Ignacio Pretelt Chaljub.

Corte Constitucional. Sentencia T-019 (17 de enero de 2011). M. P. Jorge Iván Palacio Palacio.

Corte Constitucional. Sentencia C-470 (13 de junio de 2011). M. P. Nilson Pinilla Pinilla.

Corte Constitucional. Sentencia T-802 (11 de octubre de 2012). M. P. Jorge Iván Palacio Palacio.

Corte Constitucional. Sentencia SU-897 (31 de octubre de 2012). M. P. Alexei Julio Estrada.

Corte Constitucional. Sentencia SU-070 (13 de febrero de 2013). M. P. Alexei Julio Estrada.

Corte Constitucional. Sentencia T-605 (2 de septiembre de 2013). M. P. Alberto Rojas Ríos.

Corte Constitucional. Sentencia T-156 (14 de marzo de 2014). M. P. María Victoria Calle Correa.

Corte Constitucional. Sentencia T-326 (3 de junio de 2014). M. P. María Victoria Calle Correa.

Corte Constitucional. Sentencia T-400 (26 de junio de 2014). M. P. Jorge Iván Palacio Palacio. 
Fernando Antonio Moreno González, Lina Stefania Arévalo Sanabria La prevalencia entre protección de derechos fundamentales o elementos de la naturaleza del cargo

Corte Constitucional. Sentencia T-238 (30 de abril de 2015). M. P. Martha Victoria Sáchica Méndez.

Corte Constitucional. Sentencia T-345 (5 de junio de 2015). M. P. Jorge Ignacio Pretelt Chaljub.

Corte Constitucional. Sentencia T-029 (5 de febrero de 2016). M. P. Alberto Rojas Ríos.

Corte Constitucional. Sentencia T-102 (1 de marzo de 2016). M. P. María Victoria Calle Correa.

Corte Constitucional. Sentencia T-320 (21 de julio de 2016). M. P. Alberto Rojas Ríos.

Corte Constitucional. Sentencia T-357 (6 de julio de 2016). M. P. Jorge Iván Palacio Palacio.

Corte Constitucional. Sentencia T-685 (2 de diciembre de 2016). M. P. María Victoria Calle Correa.

Corte Constitucional. Sentencia T-373 (8 de junio de 2017). M. P. Cristina Pardo Schlesinger.

Corte Constitucional. Sentencia T-420 (30 de junio de 2017). M. P. Cristina Pardo Schlesinger.

Corte Constitucional. Sentencia T-460 (18 de junio de 2017). M. P. Alberto Rojas Ríos.

Corte Constitucional. Sentencia T-499A (4 de agosto de 2017). M. P. Luis Guillermo Guerrero Pérez.

Corte Constitucional. Sentencia SU-003 (8 de febrero de 2018). M. P. Carlos Bernal Pulido.

Daza, A. (2013). Legalidad y prescripción frente a la investigación de crímenes de lesa humanidad en Colombia. Revista Iusta, 38, 205-223. DOI: https://doi.org/10.15332/ s1900-0448.2013.0038.08 
Filac (Fondo para el Desarrollo de los Pueblos Indígenas de América Latina y el Caribe) (s. f.). Definición de elementos de la matriz del sistema. Definición de los dominios. Dominio 5.2: acción afirmativa. DOI: https://doi.org/10.2307/j.ctv1xxvwr.84

García, L. (2013). El contexto de mujer en la realidad jurídico-penal colombiana: delitos sexuales y revictimización. Revista Iusta, 38, 103-113. DOI: https://doi.org/10.15332/ s1900-0448.2013.0038.04

Garzón, E. (2013). Globalización del derecho, fetichismo legal, el velo de los derechos humanos. Verba Iuris, 30, 169-181. DOI: https://doi.org/10.18041/0121-3474/ verbaiuris.30.2154

González, O. (2014). La Corte Constitucional como agente del campo jurídico colombiano: la omisión legislativa de principios constitucionales. Revista Iusta, 41, 123-137. DOI: https://doi.org/10.15332/s1900-0448.2014.0041.01

Guarín, E. (2013). Persona y realización efectiva de derechos. Revista Iusta, 38, 133-154. DOI: https://doi.org/10.15332/s1900-0448.2013.0038.05

Guarín, E. A. y Aldana, J. (2016). Estado jurisdiccional y bien común. Verba Iuris, 11(36), 13-26. DOI: https://doi.org/10.18041/0121-3474/verbaiuris.36.1001

Humbarita, J. (2015). Derecho constitucional hispanoamericano frente a la realidad institucional, manifiesta divergencia. Revista Iusta, 43, 91-118. DOI: https://doi. org/10.15332/s1900-0448.2015.0043.03

OIT (Organización Internacional del Trabajo) (4 de junio de 1952). Recomendación sobre la protección de la maternidad (núm. 95). DOI: https://doi.org/10.1111/isss.12023

República de Colombia (1991). Constitución Política.

Saidiza, H. y Carvajal, J. (2016). Crisis del Estado de derecho en Colombia: un análisis desde la perspectiva de la legislación penal. Revista Iusta, 44, 17-39. DOI: https://doi. org/10.15332/s1900-0448.2016.0044.01 
Fernando Antonio Moreno González, Lina Stefania Arévalo Sanabria La prevalencia entre protección de derechos fundamentales o elementos de la naturaleza del cargo

Vargas, Y. y Bracchi, C. (2016). La mujer latinoamericana dentro del contexto de los derechos humanos: énfasis desde la perspectiva del derecho al trabajo. Revista Iusta, 44, 75-97. DOI: https://doi.org/10.15332/s1900-0448.2016.0044.04 